\title{
LIII. On Wheatstone and Brewster's theory of binocular perspective
}

\section{W.Le Conte Stevens}

To cite this article: W.Le Conte Stevens (1881) LIII. On Wheatstone and Brewster's theory of binocular perspective , Philosophical Magazine Series 5, 12:77, 436-443, DOI: $10.1080 / 14786448108627130$

To link to this article: http://dx.doi.org/10.1080/14786448108627130

曲 Published online: 28 Apr 2009.

Submit your article to this journal ¿

Џ Article views: 3

Q View related articles $₫$ 
have the credit of this law taken away by a careless sentence like the above.

I do not think there is any thing I need add, except that I do not follow the argument by which Prof. Thompson arrives at the result that the beats of the lower notes are not subjective. There seems to me to be no proof whatever of this result.

$$
\text { Yours truly, }
$$

R. H. M. Bosanquet.

LIII. On Wheatstone and Brewster's Theory of Binocular Perspective. By W. Le Conte Stevens*.

T N 1838 Sir Charles Wheatstone $\dagger$ announced his invention 1 of the reflecting stereoscope, by means of which slightly dissimilar pictures of the same object could be simultaneously viewed in such a manner as to produce the illusion of binocular relief. The essential object attained by using this instrument he expresses by saying $\ddagger$, "the two pictures (or rather their reflected images) are placed in it at the true concourse of the optic axes." The apparent distance of the combined image is thus determined by the intersection of these axes. In a subsequent paper $\S$, published in 1852 , Wheatstone described a number of experiments with his stereoscope, by which he had investigated the effect of varying the convergence of visual lines. The result he expressed by saying\|, "The perceived magnitude of an object diminishes as the inclination of the axes becomes greater while the distance remains the same; and it increases, when the inclination of the axes remains the same while the distance diminishes." In a subsequent paragraph, however, speaking of the change in apparent magnitude of the image produced by varying the optic angle, he says $T$, "and yet, if we attentively regard it in any fixed position, it is perceived to be at a different distance." That Wheatstone had not given up the idea of apparent distance expressed in his first paper, however, is shown by his subjoining** a table of inclinations of the optic axes which correspond to different distances; it also shows the angular positions of the camera required to obtain binocular pictures

- Abstract of a memoir read before the New York Academy of Sciences, Oct. 24, 1881. Communicated by the Author.

$\dagger$ Wheatstone, "Contributions to the Physiology of Vision," Phil. Trans, 1838, part ii. Also reprinted in the Philosophical Magazine, A pril
1852, p. 241.

$\ddagger$ Ibidem, p. 245 (1852). $\quad$ Ibidem, p. $504 . \quad \|$ Ibidem, p. 507.
†ा Ibidem, p. 508. 
which shall appear at a given distance in the stereoscope in their true relief." This table is constructed from the following formula* (" $a$ denoting the distance between the two eyes, and $\theta$ the inclination of the optic axes"):-

$$
\mathrm{D}=\frac{1}{2} a \cot \frac{1}{2} \theta \text {. }
$$

From this formula it is obvious that if the axes become parallel, $\mathrm{D}$ becomes infinite; if divergent, $\mathrm{D}$ becomes negative. Wheatstone makes no reference to the attainment of optic divergence; but his stereoscope was constructed in such manner that the visual lines might be made parallel. Of the images thus produced he notes as a peculiarity $\dagger$, "although the optic axes are parallel, or nearly so, the image does not appear to be referred to the distance we should, from this cir- . cumstance, suppose it to be, but it is perceived to be much nearer."

These apparently contradictory statements of Wheatstone show how difficult it is to interpret our sensations when the conditions attendant upon normal vision are disturbed. Wheatstone notices the distortion of perspective produced by making the angle between the camera axes different from that between the visual lines when the stereograph is viewed $\ddagger$; but in this connexion he does not mention any apparent change in distance of the picture as a whole.

In 1844, Sir David Brewster published a paper§ "On the Knowledge of Distance given by Binocular Vision," in which he elaborated the idea that apparent distance is determined by intersection of visual lines, giving an interesting geometric discussion of the subject, and describing many experiments performed without the aid of the stereoscope. The intersection of the visual lines he calls the binocular centre; and for its distance from the card on which the conjugate pictures are drawn he deduces a formula, the discussion of which leads to results identical with those deduced from Wheatstone's formula. In his paper relating to the lenticular stereoscopell, and other forms of the instrument devised by him, he frequently refers to the external intersection of axes coincident in direction with the rays after refraction or reflection, but makes no reference to divergence of visual lines.

The theory of apparent distance of objects perceived in the stereoscope, to which Wheatstone, and especially Brewster, gave prominence, has been abundantly reproduced in our text-books on Physics ; indeed it is expressed either directly

* Phil. Mag. p. 512 (1852). † Ibidem, p. $514 . \quad \ddagger$ Ibidem, p. 512.

\& Edinburgh Transactions, vol. xv. p. 663 (April 1844).

|l Phil. Mag. Jan. 1852, p. 16. 
or implicitly in every explanation of the stereoscope to which I have had access, where a diagram is employed in tracing the course of rays entering the eyes. That it is misleading and should be abandoned, is shown by the fact that the perception of binocular relief and the judgment of apparent distance in the stereoscope are easy when conditions are such as to make the visual lines slightly divergent. If their intersection determines the point of sight, this would then be behind the observer's head. In taking the pictures composing the stereograph, each point in the field of view is at the intersection of i pair of secondary camera axes; and thus far, but no further, Wheatstone's formula is strictly applicable. No diagram can give more than an approximation to the truth when the pictures are viewed in the stereoscope; and not one hitherto published has exhibited any provision for the possibility of optic divergence. I have elsewhere* shown how such a diagram may be constructed by application of Hering's theory of a binocular eye (ceil de cyclope imaginaire) $\dagger$, assuming that we know the angle of convergence between the camera axes for a given point in the field of view.

The fact that optic divergence is possible with distinct binocular fusion of retinal images is not new. The use of prisms for testing the rectus muscles of the eyeballs has long been known; and Helmholtz not only mentions the use of stereographs for the same purpose, but observes the increase in apparent distance of the point of sight when divergence of visual lines is induced $\neq$. No analysis of the visual phenomena seems to have been made, however; and their important bearing upon the theory of stereoscopic perspective seems to have escaped notice. Helmholtz says $\$$ in regard to such illusions of sight, "If these images are such as could not be produced by any normal kind of observation, we judge them according to their nearest resemblance;" but comparison is scarcely satisfactory if direct analysis is possible.

I have examined many stereoscopes and stereographs in testing Brewster's theory ll, and have found that optic divergence is often necessary; hence it is unconsciously practised by nearly every one who uses them. What is really requisite is not that the visual lines shall converge, but that the eyes shall receive upon corresponding retinal points the images of

* American Journal of Science, Nov. and Dec. 1881.

+ Hering, Beiträge zur Physiologie ; or Helmholtz, Opt. Physiologique, p. 777 (edit. 1867).

$\ddagger$ Opt. Phys. pp. 616 \& 828.

$\S$ 'Popular Lectures on Scientific Subjects,' p. 307 (tr. 1873).

II American Journal of Science, Nov, and Dec. 1881. 
corresponding points on the stereograph. The relative positions of the different parts of the externally projected binocular image is determined mainly by the stereoscopic displacement in the pair of pictures viewed. This in turn is determined by the degree of convergence of the camera axes; while the relation between the visual lines of the observer in the stereoscope may be either convergence, parallelism, or divergence. It is not, however, a matter of indifference which of these relations is assumed. Theoretically the visual lines should meet at an angle the same as that between the camera axes, when a given point is examined; practically this is rarely ever the case. The distance between corresponding stereograph points is adjusted to secure, if possible, comfort to an average pair of eyes in viewing the picture; and the same stereograph may necessitate convergence of visual lines for one observer, divergence for another, in order that binocular fusion be attained.

In studying the effect of varying the optic angle while a given stereograph is examined, I have found a modification of Wheatstone's reflecting stereoscope to be valuable. The arms were made to glide under a divided circle in such manner that, from a given point on either of the conjugate pictures, the angle of incidence at the surface of each mirror could be varied from $0^{\circ}$ to $60^{\circ}$. When its value is $45^{\circ}$ the visual lines must be parallel, if the image is seen binocularly; if less than $45^{\circ}$, they must converge; if greater, they must diverge. Calling angles of convergence positive, I was able to vary the optic angle from $-7 \frac{10}{2}$ to $+80^{\circ}$, though clear and steady vision was not possible through so wide a range. Placing the conjugate pictures each at a fixed distance, such as 50 centim., this being the sum of the lengths of the incident and reflected rays, the apparent distance of the binocular image should be 50 centim. when the arms of the instrument are so disposed as to make the optic angle about equal to $7^{\circ} 20^{\prime}$. The effect upon the combined image may then be noted for any change in the relation between the visual lines.

Helmholtz ${ }^{*}$ has shown that the visual lines are not coincident with the true optic axes of the eyeballs; but since each is practically axial in its relation to the crystalline lens, it will involve no confusion to call them visual axes, while the angle, $\alpha$, between them is still called the optic angle. If an isosceles triangle be constructed whose base, $a$, is the interocular line, then for the distance, D, of its vertex from either optic centre, we have

$$
\mathrm{D}=\frac{1}{2} a \operatorname{cosec} \frac{1}{2} \alpha \text {. }
$$

* Opt. Phys. p. 93 (edit. 1867). 
The optic vertex is simply Brewster's "binocular centre." In normal binocular vision of near objects, the distance of the point of sight is sufficiently nearly given by this formula, while the subjective effect is that of the superposition of the two retinal images in a central binocular (cyclopean) eye*, the two visual axes being combined into a single median line, along which distance is estimated. These lines in turn have no objective existence; and their intersection really cannot determine any external point. Any effect due to axial convergence is merely the interpretation which experience bas taught the observer to put upon the sensation of muscular tension, as the internal rectus muscles contract. This interpretation may be strengthened or antagonized by what other conditions suggest; and the estimate of distance on the combined median line is modified accordingly. The direction of the combined image is along this median, whether the visual axes be convergent, parallel, or divergent.

If the conjugate pictures selected be the simplest possible, so that all kinds of perspective are eliminated except that due to stereoscopic displacement, there are still left three elements to consider, which can never be entirely dissociated. These are:-

I. The optic angle, interpreted by the sensation of tension in the rectus muscles of the eyeballs.

II. The focal adjustment, interpreted by the tension in the ciliary muscle encircling the crystalline lens.

III. The visual angle, interpreted by recognition of the retinal area impressed.

In normal vision, these elements conduce to the same visual effect without becoming separately manifested to the consciousness of the individual. In the stereoscope they may conflict among themselves; and the result is modification of judgment, attended with some uncertainty.

Let us now assurne the arms of our stereoscope to bo so turned upon their pivot as to change the value of $\alpha$ from $7^{\circ} 20^{\prime}$ to $37^{\circ} 20^{\prime}$, the interocular distance, $a$, being taken as 64 millim. Applying our formula, we find $D=10$ centim. The focal adjustment, however, must still be for an image 50 centim. distant, if distinct vision is attained. Strong contraction of the internal rectus muscles is habitually associated with nearness of the point of sight, and accompanied with strong ciliary contraction. But in the present case the effort to secure distinct vision implies relaxation of the ciliary muscles, the effect of which is to suggest greater distance of the point

* Le Conte, 'Light,' New York, 1881, pp. 213-268; or American Journal of Science, ser. 3, rol. i. p. 33 et seq. 
of sight than is suggested by the tension of the rectus muscles; and there is partial dissociation between actions generally associated. Finally, the visual angle has remained constant; and this tends to produce the idea of constancy in distance. Of the three elements, however, the first is found most important; and the combined effect is that the image appears 18 or 20 centim. distant, the judgment being quite uncertain. The apparent area and depth of the external image are diminished approximately in the ratio of the diminished distance.

Let the arms of the stereoscope be now pushed back till $\alpha=-5^{\circ}$. Relaxation of the internal rectus and contraction of the external rectus muscles is habitually associated with recession of the point of sight; and in this case it is carried beyond the limit of axial parallelism. But, again, the focal adjustment is for a point only 50 centim. in front; and the visual angle is constant. Of the three elements the last is now most important; and the combined effect is that the image appears about 60 or 70 centim. distant, with corresponding increase in apparent area and depth.

In the accompanying figure (fig. 1) I have shown the result

Fig. 1.

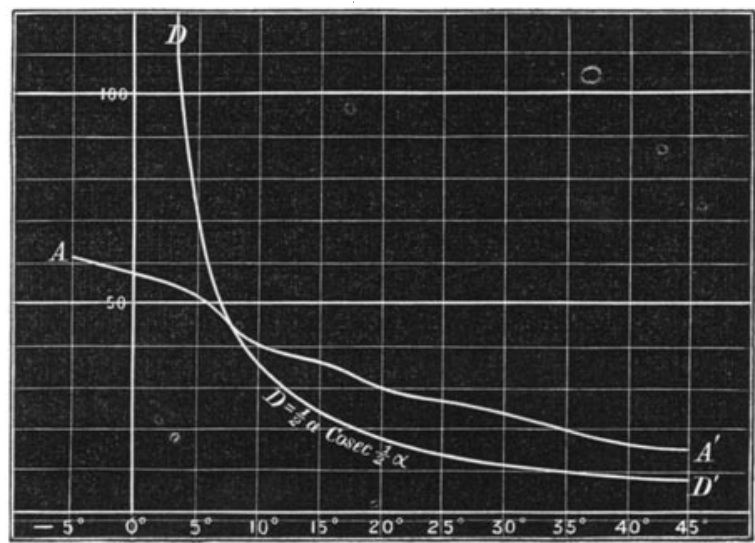

of experiments conducted at different times during the last few months. The stereoscope was manipulated by an assistant, who varied the optic angle in the most irregular order, recording its values and my corresponding estimates of distance, while I was kept ignorant of these records until the entire list of estimates had been completed. Six independent series, of eighteen estimates each, were made; and the curve $A A^{\prime}$ expresses the mean result, the values of the optic angle being taken as abscissas and estimated distances as ordinates, the 
true distance of the stereograph being 50 centim. $\mathrm{D} \mathrm{D}^{\prime}$ is the curve whose equation is $\mathrm{D}=\frac{1}{2} a \operatorname{cosec} \frac{1}{2} \alpha$, the value of $a$ being my interocular distance, 60 millim. As might be expected, the probable error is large, being about \pm 8 millim.; and the curve $\mathrm{A} \mathrm{A}^{\prime}$ is by no means regular, though its general import is unmistakable. It cuts the theoretic curve near the point corresponding to $\alpha=7^{\circ} 20^{\prime}$, but rather lower than might have been anticipated.

The stereograph employed was one of the full moon, the two pictures being of course cut apart, and so arranged as to produce conversion of relief, thus destroying any resemblance to known bodies; while objects for comparison were excluded from the binocular field of view. All estimates of distance were for the foreground. For very large positive optic angles the dissociation between axial and focal adjustments becomes extremely difficult; and distinct vision at the distance of 50 centim. is then impossible. For negative values focalization is comparatively easy; but beyond $-6^{\circ}$ the unaccustomed strain upon the external rectus muscles produces unsteadiness of vision. As limits, therefore, $-5^{\circ}$ and $+45^{\circ}$ were selected.

Although such employment of the muscles of the eyes is unusual when carried to the extent implied in these experiments, and the disturbance of natural coordination is at first confusing, the use of the stereoscope nearly always necessitates such disturbance, to a limited extent, and is hence not unfrequently productive of discomfort. Most persons, however, who possess healthy eyes will find it possible to secure binocular combinution of the conjugate diagrams in fig. 2 , if viewed in the stereoscope. For this purpose they are placed at the bottom of the page, which may be rested at the proper

Fig. 2.
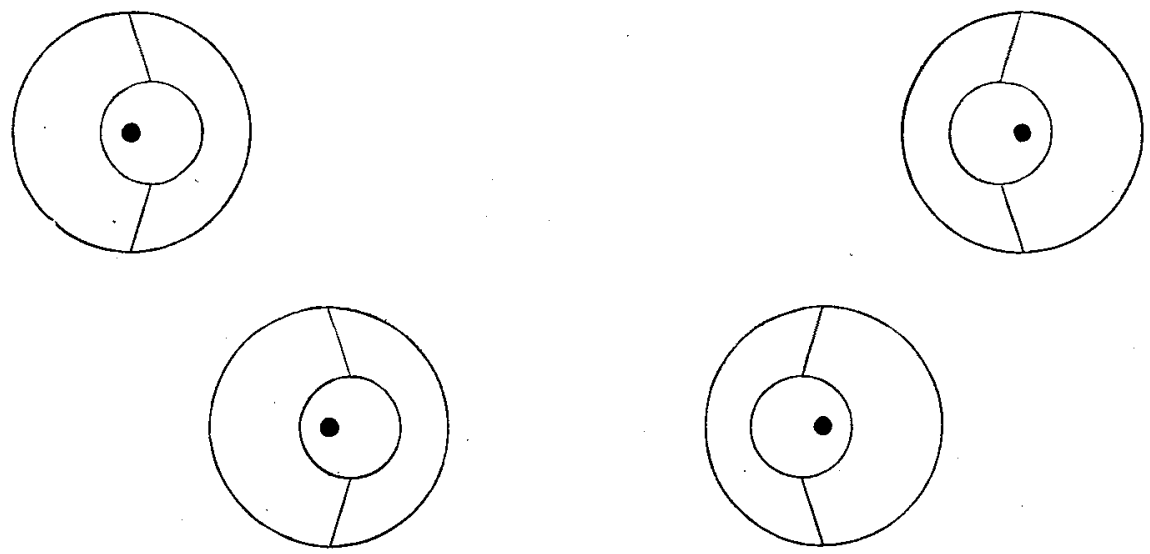
distance in front of the semi-lenses of the stereoscope. When the lower pair are seen, by axial convergence, as a truncated cone, the upper pair are seen separately and monocularly, without the appearance of relief. For binocular combination of the upper pair divergence of visual lines is required, assuming an average pair of eyes and an average lenticular stereoscope, at least as found in New York. The truncated cone now appears larger, deeper, and more distant. It is unnecessary to explain why the background dot should appear double when the foreground circle is seen single, and vice vers $\hat{a}$.

In the course of these experiments, extending over many months, it has been found that, although the coordination of muscular actions in the eyes is commonly directed only to the attainment of perfect vision, their dissociation is largely under the control of the will. Not only is it possible directly to diverge the visual lines without employing any external points of fixation, but I find it not difficult to contract the ciliary muscle strongly, thereby destroying the distinctness of distant vision, while the relation between the visual lines undergoes scarcely any noticeable variation. Certain peculiar visual effects result from this; but the discussion of them must be reserved at present.

40 West 40th Street, New York.

\section{Notices respecting New Books.}

Conic Sections treated Geometrically. By S. HoLker HasLam, B.A., and J. Edwards, B.A. London: Longmans. 1881. Pp. 137.

THE authors start from the usual Focus and Directrix definition 1 of the curve, and call to their aid what they call the Auxiliary Circle of a Point. This is the circle first used, so far as we are aware, by Boscovich in his Sectionum Conicarum Elementa (1754), but without a name: of its use he writes:-"Mirum sane quam fœeunda est hæc constructio, quam tyroni exercendo apta. Plurima quidem ex eâ inferri possunt theoremata et pleraque utilissima, ac iterum foecunda." Rediscovered by George Walker (1794), and named by him the Generating Circle, it has again come to the front in Mr. Charles Taylor's book, and there poses as the Eccentric circle of a point. It certainly furnishes a very neat basis for operating upon the Sections; and its usefulness is extended in a neat way by our Authors to what they call Focal Projection. The first five chapters give the familiar properties of these curves; the sixth treats of curvature; the seventh of the Right circular cone; the eighth of Transversals leading up to the above-named Focal Projection in chapter nine, and Orthogonal Projection in chapter ten. Six sections are devoted to Exercises at the end of the book. The proofs have a freshness about them dependent upon the introduction of 